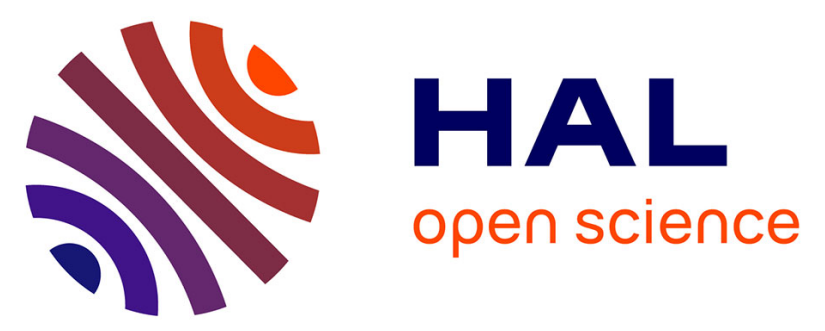

\title{
Etude sur les toxines produites par Rosellinia necatrix (Hart.) Berl
}

Denis D. Tourvieille de Labrouhe

\section{To cite this version:}

Denis D. Tourvieille de Labrouhe. Etude sur les toxines produites par Rosellinia necatrix (Hart.) Berl. Agronomie, 1986, 6 (2), pp.195-201. hal-00884865

\section{HAL Id: hal-00884865 https://hal.science/hal-00884865}

Submitted on 1 Jan 1986

HAL is a multi-disciplinary open access archive for the deposit and dissemination of scientific research documents, whether they are published or not. The documents may come from teaching and research institutions in France or abroad, or from public or private research centers.
L'archive ouverte pluridisciplinaire HAL, est destinée au dépôt et à la diffusion de documents scientifiques de niveau recherche, publiés ou non, émanant des établissements d'enseignement et de recherche français ou étrangers, des laboratoires publics ou privés. 


\section{Etude sur les toxines produites par Rosellinia necatrix (Hart.) Berl.}

Denis TOURVIEILLE DE LABROUHE

I.N.R.A., Station de Pathologie végétale, 12, avenue du Brézet, F 63039 Clermont-Ferrand Cedex

RÉSUMÉ

Rosellinia necatrix est un champignon ascomycète, agent du pourridié laineux de certaines plantes ornementales et cultures fruitières.

L'étude du comportement d'organes excisés des hôtes cultivés en France vis-à-vis des toxines produites par le champignon in vitro et in vivo montre que la spécificité d'action de ces dernières ne correspond pas à celle du champignon. Cependant, sur les pommiers, on observe une correspondance entre la sensibilité des génotypes de l'hôte au pathogène et aux toxines; il apparaît également une certaine relation entre le pouvoir pathogène des différents isolats et leur aptitude à produire des toxines in vitro.

La discussion porte sur les déterminants du pouvoir pathogène de $R$. necatrix.

Mots clés additionnels : Dematophora necatrix, pourridié laineux, Malus pumila, pommier.

Rosellinia necatrix is an ascomycete causing white root rot of certain ornamental and fruit species. The reaction of some host species to the toxins produced by the fungus in vitro and in vivo showed that the specificity of action of these toxins did not correspond to that of the fungus. However, for apple there was a correspondence between susceptibility to the pathogen and to the toxins; there was also a correlation between the pathogenicity of different isolates and their ability to produce toxins in vitro. The factors determining the pathogenicity of $R$. necatrix are discussed.

Additional key words : Dematophora necatrix, white root rot, Malus pumila, apple.

\section{INTRODUCTION}

Rosellinia necatrix (Hart.) Berl. est un champignon ascomycète, responsable du pourridié laineux ou pourridié blanc. Cette maladie se rencontre en France sur un grand nombre d'hôtes tels que les arbres fruitiers (pommier, cerisier, ...), les plantes ornementales (jasmin, pivoine, ...) et les plantes potagères (fraisier, ...) (GuILLAUMIN et al., 1982). L'évolution de la maladie pourrait faire penser à l'intervention de toxines ; en effet, on observe assez fréquemment la mort par jaunissement et flétrissement de jeunes arbres dont seulement une partie du système racinaire est envahie par le champignon.

La toxicité des filtrats de culture du Rosellinia a été mise en évidence par ABE \& KONO $(1955,1957)$. Ils ont obtenu sur fève des symptômes identiques à ceux causés par Cercospora fabae Fautr. et, sur théier, les mêmes flétrissements que ceux provoqués par le pourridié laineux. CHEN (1960) a obtenu des résultats analogues sur la croissance de plantules de riz.
Nous avons cherché à savoir si les substances phytotoxiques mises en évidence dans les filtrats de culture de Rosellinia jouaient un rôle dans le pouvoir pathogène de ce champignon vis-à-vis des plantes qui sont ses hôtes dans notre pays (le fraisier, la pivoine, le jasmin, le cerisier et surtout le pommier).

\section{MATÉRIEL ET MÉTHODES}

\section{A. Le champignon}

Nous avons travaillé avec 5 isolats de Rosellinia Rn 8, Rn 9, Rn 17, Rn 22 et Rn 25 (tabl. 1).

Les cultures d'entretien sont réalisées sur un milieu gélosé (malt 1 p. 100) en boîte de Petri. Elles sont placées dans une étuve à $23 \pm 0,5^{\circ} \mathrm{C}$ et à l'obscurité. Les isolats sont repiqués tous les mois.

Les cultures sur milieu liquide sont obtenues en bouteille de Roux d'1 litre. Nous ensemençons $200 \mathrm{ml}$ de milieu (CHEN, 1960) avec une pastille de gélose prélevée 
TABLEAU 1

Caractéristique des 5 isolats de Rosellinia necatrix. Description of 5 Rosellinia necatrix isolates.

\begin{tabular}{llll}
\hline \hline Isolat & Hôte & \multicolumn{1}{c}{ Origine géographique } & Poids sec de mycélium en grammes (') \\
\hline Rn 8 & Fraisier & Clermont-Ferrand (Puy-de-Dôme) & $1,79 \pm 0,33$ \\
Rn 9 & Pommier & Allonnes (Maine-et-Loire) & $2,25 \pm 0,52$ \\
Rn 17 & Cerisier & Solliès-Pont (Var) & $1,76 \pm 0,38$ \\
Rn 22 & Pivoine & Sainte-Anne d'Evenos (Var) & $2,26 \pm 0,50$ \\
Rn 25 & Jasmin & Grasse (Alpes-Maritimes) & $1,36 \pm 0,43$ \\
\hline \hline
\end{tabular}

(1) Pour $200 \mathrm{ml}$ de milieu de culture après $30 \mathrm{j}$ d'incubation (15 répétitions).

à la périphérie d'une culture en boîte de Petri, âgée de $6 \mathrm{j}$. Les bouteilles sont placées en position horizontale dans une étuve à $23 \pm 0,5^{\circ} \mathrm{C}$ et à l'obscurité.

L'inoculum est préparé en cultivant les isolats sur baguettes de noisetier (TOURVIEILLE, 1982). L'incubation s'effectue à $22 \pm 2{ }^{\circ} \mathrm{C}$ et dure $60 \mathrm{j}$. L'infection des plantes en pot consiste à enfoncer dans la terre, à $5 \mathrm{~cm}$ du collet, une baguette colonisée par le champignon.

\section{B. Le matériel végétal}

Les études ont porté sur 4 porte-greffes de pommier : M 7, M 9, M 26 et MM 106 ; sur 2 porte-greffes de cerisier : merisier F 12-1 et « Sainte-Lucie SL 64 »; sur une variété de fraisier : "Red Gauntled "; une espèce de jasmin : Jasminum primulinum et une espèce de pivoine : Paeonia coralina. Toutes ces plantes sont, dans la nature, sensibles au pourridié laineux.

Nous avons également utilisé, pour l'étude du pouvoir pathogène du champignon et pour la recherche des toxines dans le végétal infecté, de jeunes plants de pommier obtenus à partir de pépins de la variété " Golden delicious $»$.

Les plants débarrassés de leur terre de pépinière sont empotés dans un mélange stérilisé à la vapeur. Ce mélange est constitué à parts égales de sable de rivière, de terre de Limagne et de terre de bruyère. Les pots sont placés sous un abri plastique et sont arrosés 2 fois par semaine.

\section{Etude des toxines}

\section{Extraction}

CHEN (1960) extrayait les toxines du filtrat de culture par le chloroforme puis il les purifiait par passage sur une série de colonnes à chromatographie. Après extraction au chloroforme nous avons séparé les différentes molécules présentes dans l'extrait, sur plaque de gel de silice selon le protocole suivant :

A partir d'une culture sur milieu liquide

A partir du végétal infecté

Passage du mycélium sur un linge et récupération du filtrat

Autoclavage durant $20 \mathrm{mn}$ à $110^{\circ} \mathrm{C}$
Les différents organes sont finement broyés et additionnés d'eau permutée

Autoclavage durant $20 \mathrm{mn}$ à $110^{\circ} \mathrm{C}$, passage sur un linge et récupération du filtrat

Ajustage au pH 7 avec $\mathrm{NaOH}$ ou $\mathrm{H}_{2} \mathrm{SO}_{4}$ dilué

Double extraction au chloroforme ( $10 \mathrm{p} .100 \mathrm{du}$ volume)

Concentration de la phase soluble à l'évaporateur sous vide $\left(55^{\circ} \mathrm{C}\right)$

Dépôt sur une plaque de gel de silice type Silicagel 60 F254

Elution par le mélange acétate d'éthyle-chloroforme (1/1)

Découpage de la zone comprise entre les $\mathrm{Rf} 0,1$ et 0,5

Reprise des substances dans de l'acétate d'éthyle

Mise en solution dans l'eau à $55{ }^{\circ} \mathrm{C}$ par évaporation sous vide du solvant

Réajustement de la solution à la concentration désirée 


\section{Test sur végétal}

Les rameaux ou les feuilles sont maintenus en survie dans de petits flacons contenant la solution aqueuse des extraits purifiés à tester. La lecture porte sur l'observation des symptômes foliaires : nécrose, flétrissement ou dessèchement. Nous avons utilisé l'échelle de notation suivante :

degré 1 : apparition des premiers signes de toxicité 2 : nécrose ou flétrissement de 25 p. 100 de la surface foliaire

3 : nécrose ou flétrissement de 50 p. 100 de la surface foliaire

4 : nécrose ou flétrissement de 100 p. 100 de la surface foliaire.

Un témoin est constitué avec un extrait du milieu non ensemencé. La lecture est arrêtée lorsque le degré 4 est atteint ou quand le témoin montre des symptômes de flétrissement.

\section{RÉSULTATS}

\section{A. Réaction des plantes hôtes au filtrat de culture purifié}

\section{Comparaison d'hôtes de genre différent}

Les études ont porté sur des organes excisés de diverses plantes-hôtes potentielles du Rosellinia. Les jeunes rameaux de pommier, de cerisier et de jasmin, ainsi que les feuilles de fraisier et de pivoine sont maintenus en survie dans les extraits purifiés des filtrats de culture des 5 isolats (5 répétitions par isolats).

a) Types de symptômes : les végétaux ne réagissent pas d'une manière identique (tabl. 2), sans qu'il y ait interaction entre hôtes et isolats.

Sur les feuilles de pommier, on observe une nécrose des nervures qui envahit progressivement le limbe avec ou sans dessèchement. Les feuilles de merisier et de Sainte-Lucie se décolorent, puis se dessèchent et tombent. Les feuilles de fraisier, de pivoine et de jasmin présentent des taches nécrotiques internervaires qui sont suivies d'un dessèchement pour le fraisier et la pivoine et de la chute des feuilles pour le jasmin.

b) Evolution des symptômes : les observations sont regroupées dans le tableau 3 .

Les hôtes se comportent très différemment vis-à-vis des substances toxiques produites in vitro par Rosellinia. C'est le pommier qui réagit le plus rapidement, il a été utilisé comme plante hôte dans les études ultérieures.

\section{Etude de 4 porte-greffes de pommier}

Vingt plantes de chaque porte-greffes ont été inoculées avec des baguettes de noisetier colonisées par l'isolat $\mathrm{Rn} \mathrm{17.} \mathrm{Les} \mathrm{vitesses} \mathrm{de} \mathrm{mortalité} \mathrm{(fig.} \mathrm{1)} \mathrm{per-}$ mettent de classer 3 porte-greffes sur les 4 en fonction de leur sensibilité au pourridié laineux.

$$
\text { MM } 106<\text { M } 9<\text { M } 7
$$

TABLEAU 2

Symptômes de toxicité de l'extrait purifié des filtrats de culture de Rosellinia necatrix (tous isolats confondus) sur différentes espèces. Toxicity symptoms for different species after treatment with extracts from Rosellinia necatrix culture filtrates.

\begin{tabular}{|c|c|c|c|c|c|}
\hline \multirow[b]{2}{*}{ Hôtes } & \multicolumn{4}{|c|}{ Symptômes sur feuilles } & \multirow[b]{2}{*}{ Symptômes sur tige } \\
\hline & Nécrose du limbe & Décoloration & Dessèchement & Chute & \\
\hline Pommier M 7 (r.f.) & $\begin{array}{l}\text { Marron clair débutant au niveau } \\
\text { des nervures }\end{array}$ & - & - & - & \multirow[b]{2}{*}{ Nécrose } \\
\hline Pommier M 9 (r.f.) & $\begin{array}{l}\text { Marron foncé débutant au niveau } \\
\text { des nervures }\end{array}$ & - & - & - & \\
\hline Pommier M 26 (r.f.) & $\begin{array}{c}\text { Marron clair débutant au niveau } \\
\text { des nervures }\end{array}$ & - & - & - & \multirow{4}{*}{$\begin{array}{l}\text { vaisseaux } \\
\text { conducteurs }\end{array}$} \\
\hline Pommier MM 106 (r.f.) & $\begin{array}{c}\text { Petites taches brunes au niveau } \\
\text { des nervures }\end{array}$ & - & + & - & \\
\hline Cerisier merisier F 12-1 (r.f.) & $\begin{array}{c}\text { Marron clair débutant au niveau } \\
\text { des nervures }\end{array}$ & + & + & + & \\
\hline Cerisier Sainte-Lucie SL 64 (r.f.) & Absence de nécrose & + & - & + & \\
\hline Jasmin (r.f.) & $\begin{array}{c}\text { Petites taches peu colorées } \\
\text { internervaires }\end{array}$ & - & - & + & $\begin{array}{l}\text { Nécrose de la base } \\
\text { et du milieu de tige } \\
\text { suivie du flétrissement } \\
\text { de la partie apicale }\end{array}$ \\
\hline Pivoine (f.) & Nécrose claire du limbe & - & + & - & \\
\hline Fraisier (f.) & $\begin{array}{l}\text { Taches internervaires } \\
\text { translucides }\end{array}$ & - & + & - & \\
\hline
\end{tabular}

(r.f.) = rameau feuillu ; (f.) = feuille. 
TABLEAU 3

Délais (en heures) d'apparition des symptômes de toxicité des filtrats de cultures de 5 isolats de Rosellinia necatrix chez différentes espèces végétales.

Time (in $h$ ) necessary for toxicity symptom appearance for different hosts after treatment with culture filtrates from 5 Rosellinia necatrix strains.

\begin{tabular}{|c|c|c|c|c|c|c|c|c|c|}
\hline \multirow{3}{*}{ Espèces végétales } & \multicolumn{5}{|c|}{ Nombre de répétitions avec } & \multicolumn{4}{|c|}{ Classe des symptômes de toxicité (en h) } \\
\hline & $\operatorname{Rn} 8$ & Rn 9 & $\operatorname{Rn} 17$ & Rn 22 & $\operatorname{Rn} 25$ & 1 & 2 & 3 & 4 \\
\hline & 5 & 5 & 5 & 5 & 5 & 22 & 27 & 33 & 41 \\
\hline M 9 (r.f.) & 5 & 5 & 5 & 5 & 5 & 29 & 34 & 40 & 51 \\
\hline M 26 (r.f.) & 5 & 5 & 5 & 5 & 5 & 37 & 54 & $-\left({ }^{*}\right)$ & - \\
\hline M 106 (r.f.) & 5 & 5 & 5 & 5 & 5 & 37 & 46 & 53 & 63 \\
\hline Pivoine (r.f.) & 3 & 3 & 3 & 3 & 2 & 175 & $-\left({ }^{*}\right)$ & - & - \\
\hline Jasmin (r.f.) & 5 & 5 & 5 & 5 & 4 & 201 & $-(*)$ & - & - \\
\hline Fraisier (f.) & 5 & 5 & 5 & 5 & 5 & 52 & 57 & 64 & 71 \\
\hline Cerisier Sainte-Lucie (r.f.) & 5 & 5 & 5 & 5 & 5 & 233 & 260 & 291 & 324 \\
\hline Cerisier merisier (r.f.) & 5 & 5 & 5 & 4 & 4 & 181 & $-\left(^{*}\right)$ & - & - \\
\hline
\end{tabular}

$\left({ }^{*}\right)$ Flétrissement des témoins placés dans l'extrait du milieu de culture non ensemencé.

(r.f.) sur rameaux feuillus; (f.) sur feuilles.

Le porte-greffes M 26 n'a pas été détruit à 100 p. 100 et cela, malgré une sensibilité précoce (fig. 1).

Les rameaux des 4 porte-greffes testés pour leur résistance au filtrat de culture du champignon ont donné les résultats du tableau 3 . Les vitesses d'apparition des symptômes nous donnent le classement suivant :

$$
\text { MM } 106<\text { M } 9<\text { M } 7 .
$$

Comme dans le cas des infections avec le champignon, le porte-greffes M 26 présente, vis-à-vis du filtrat, un comportement différent de celui des 3 autres porte-greffes : les rameaux réagissent assez rapidement mais l'évolution des symptômes est beaucoup plus lente et n'atteint pas le degré 4 .

\section{Corrélation entre sensibilité des hôtes au pathogène et aux toxines}

Les plantes-hôtes étudiées peuvent être séparées en 2 groupes:

a) Plantes très sensibles aux substances toxiques: les pommiers et le fraisier réagissent très fortement aux toxines; après seulement $60 \mathrm{~h}$, leurs feuilles sont entièrement nécrosées.

Pour les porte-greffes de pommier étudiés, le classement établi en fonction de leur résistance au pourridié laineux est identique à celui établi en fonction de leur résistance aux toxines. Il semble donc que la résistance aux toxines et celle à la maladie soient corrélées positivement et donc que la résistance d'un porte-greffes de pommier aux toxines produites in vitro par Rosellinia détermine sa résistance au pourridié laineux.

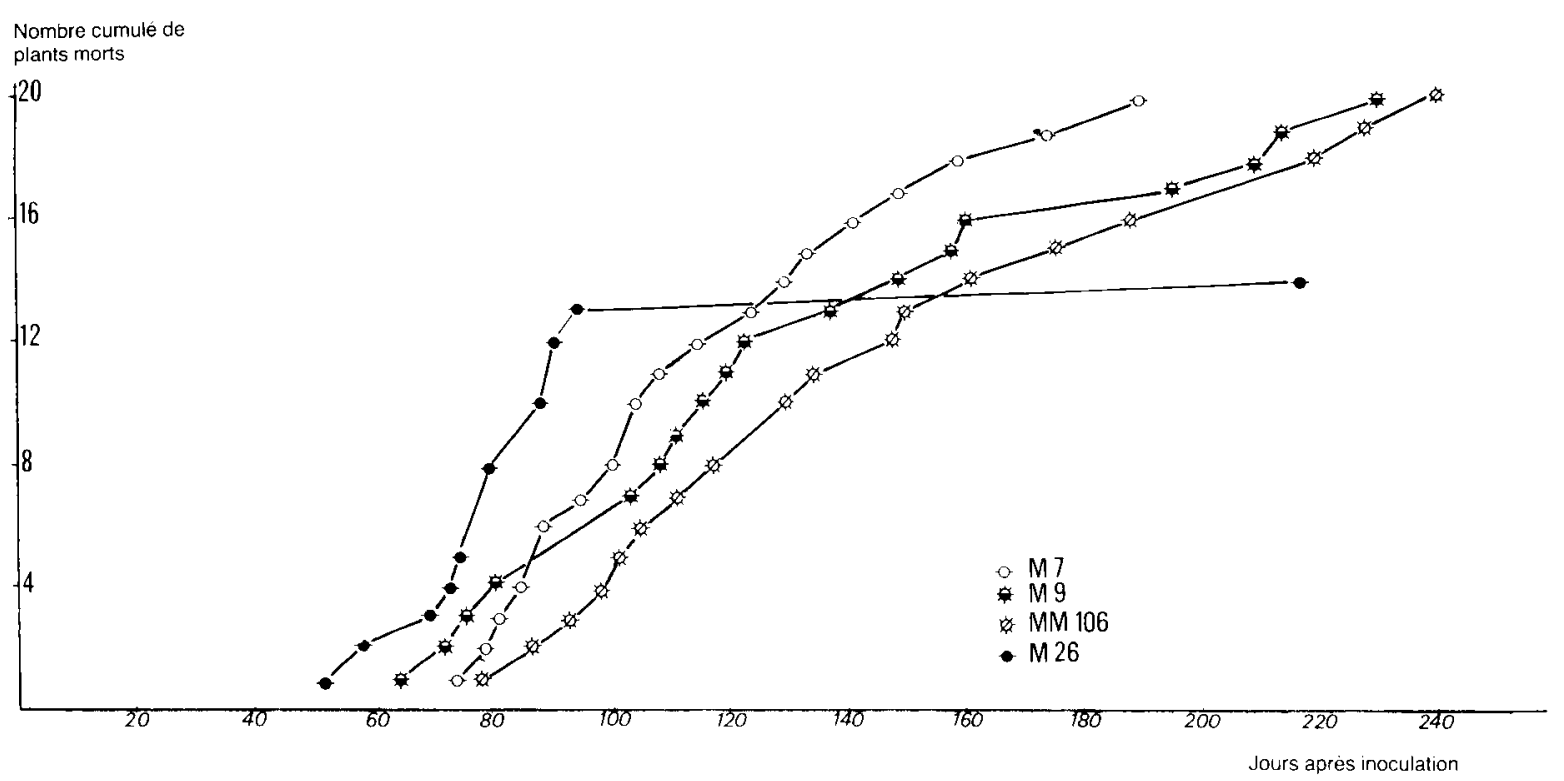

Figure 1

Vitesse de mortalité de 4 porte-greffes de pommier infectés en pot par l'isolat $R n 17$ (20 répétitions). 
b) Plantes peu ou non sensibles aux substances toxiques : les cerisiers, le jasmin et la pivoine ne montrent des symptômes que tardivement (après $100 \mathrm{~h}$ ). L'évolution de ces symptômes est très lente. Le relatif bon comportement de ces espèces aux toxines semble indiquer que le pouvoir pathogène du champignon vis-à-vis de ces hôtes est lié à d'autres facteurs qu'à l'élaboration de toxines véhiculées par la sève.

La spécificité d'action des toxines ne correspond pas toujours à celle du champignon. En effet, les cerisiers, le jasmin et la pivoine, plantes affectées par le pourridié laineux (GUILLAUMIN et al., 1982), sont peu sensibles aux toxines de nos souches pourtant isolées de ces mêmes hôtes.

\section{B. Corrélation entre le pouvoir pathogène et la capacité à produire des toxines in vitro, chez 5 isolats}

De jeunes plants issus de semis de pépins (génétiquement hétérogènes), âgés de 2 mois (stade 8 feuilles) ont été infectés à l'aide de baguettes de noisetier colonisées par les 5 isolats (21 pommiers par isolat). Les délais moyens entre l'infection et la mort des plantes (fig. 2) permettent de classer les isolats de la manière suivante (pouvoir pathogène croissant) :

$$
\operatorname{Rn} 8<\operatorname{Rn} 25<\operatorname{Rn} 9<\operatorname{Rn} 22<\operatorname{Rn} 17 \text {. }
$$

Nous avons comparé les délais de dépérissement des rameaux de 3 porte-greffes (M 7, M 9, MM 106) maintenus en survie dans les solutions aqueuses contenant les toxines des 5 isolats (tabl. 4). La concentration des solutions testées correspond, pour chaque isolat, à la quantité de toxines produites par $6 \mathrm{~g}$ de mycélium (poids sec) diluée dans $200 \mathrm{ml}$ d'eau permutée. Les délais moyens d'apparition des symptômes de degré 4 , statistiquement différents, nous permettent de classer les isolats comme suit en fonction de leur
TABLEAU 4

Analyse des délais d'apparition du symptôme de degré 4 sur les rameaux de 3 porte-greffes de pommier maintenus en survie dans les extraits purifiés des filtrats de culture de 5 isolats de Rosellinia necatrix.

Analysis of the time necessary for symptoms to appear (category 4) on the branches of 3 apple rootstocks growing in extracts from culture filtrates of 5 Rosellinia necatrix isolates.

\begin{tabular}{|c|c|c|c|c|}
\hline $\begin{array}{l}\text { Porte-greffes } \\
\text { Isolats }\end{array}$ & M 7 & M 9 & MM 106 & $\begin{array}{l}\text { Moyenne } \\
/ 15\end{array}$ \\
\hline $\mathrm{Rn} 8$ & 43,00 & 62,40 & 69,40 & 58,27 \\
\hline $\operatorname{Rn} 9$ & 41,00 & 50,80 & 65,80 & 52,53 \\
\hline $\operatorname{Rn} 17$ & 38,80 & 43,00 & 51,60 & 44,47 \\
\hline $\operatorname{Rn} 22$ & 38,60 & 47,40 & 61,40 & 49,00 \\
\hline $\operatorname{Rn} 25$ & 45,20 & 54,20 & 67,00 & 55,47 \\
\hline \multirow[t]{2}{*}{ Moyenne/25 } & 41,32 & 51,48 & 63,04 & \\
\hline & & \multicolumn{2}{|c|}{ F calculé } & F lu à 5 p. 100 \\
\hline \multicolumn{2}{|c|}{$\begin{array}{l}\text { entre porte-greffes } \\
\text { entre isolats } \\
\text { interaction }\end{array}$} & \multicolumn{2}{|c|}{$\begin{array}{c}\text { 133,85 H.S. } \\
19,94 \text { H.S. } \\
2,73 \text { n.s. }\end{array}$} & $\begin{array}{l}5,00 \\
3,82 \\
2,85\end{array}$ \\
\hline
\end{tabular}

capacité à produire des toxines :

$$
\operatorname{Rn} 8<\operatorname{Rn} 25<\operatorname{Rn} 9<\operatorname{Rn} 22<\operatorname{Rn} 17 .
$$

Les 2 classements obtenus sont identiques. Il semble donc que le pouvoir pathogène de chaque isolat, au moins sur pommier, soit corrélé avec son aptitude à produire des toxines et donc que les toxines produites par les différents isolats jouent un rôle non négligeable dans leur pouvoir pathogène sur pommier. Il n'y a pas d'interaction entre les porte-greffes et les isolats de Rosellinia.

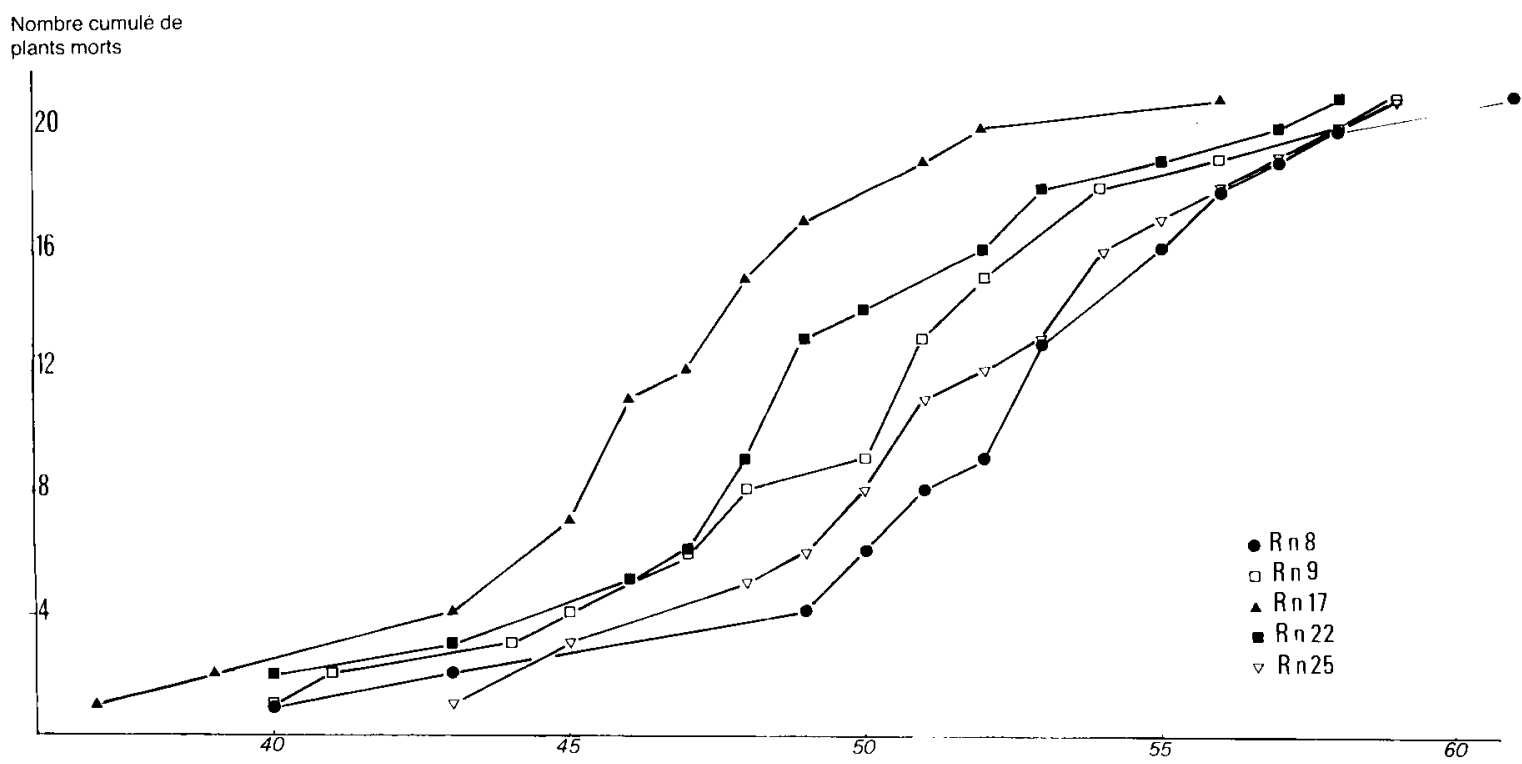

Jours après inoculatıon

Figure 2

Vitesse de mortalité des plantules de pommier infectées par 5 isolats de Rosellinia necatrix (2l répétitions).
Rate of mortality for apple seedlings inoculated with 5 Rosellinia necatrix isolates (2I replicates). 


\section{Présence des substances phytotoxiques dans la plante malade}

Nous avons récupéré séparément les feuilles, les racines et les tiges de jeunes plants issus de semis de pépins âgés de 6 mois et morts de pourridié laineux, suite à l'infection par les 5 isolats de Rosellinia. L'essai a porté sur 105 plants infectés. Les 3 extraits (racines, tiges et feuilles) ont été ramenés à $150 \mathrm{ml}$. Un témoin est constitué par un extrait de plantes saines (tous organes confondus).

Nous avons comparé les symptômes de toxicité de ces extraits à ceux obtenus avec le filtrat de culture purifié de l'isolat Rn 17 (tabl. 5).

\section{Production de toxines in vivo}

L'extrait obtenu à partir des racines infectées (envahies par le mycélium) est fortement toxique pour les rameaux de pommier, Rosellinia produit donc des toxines non seulement in vitro mais également à l'intérieur du végétal. Cet extrait provoque des symptômes identiques à ceux obtenus avec le filtrat de culture purifié, après seulement $50 \mathrm{~h}$.

\section{Migration des toxines dans la plante}

Le fait que les extraits obtenus à partir des feuilles et des tiges soient également toxiques (bien que plus faiblement) montre que ces toxines sont véhiculées pour une part non négligeable par la sève.

\section{DISCUSSION}

Trois catégories de facteurs sont susceptibles d'intervenir dans l'infection du pommier par Rosellinia :

- Les forces mécaniques : rupture des couches cellulaires de la plante par la pression résultant de la multiplication cellulaire du champignon au sein d'un organe agrégé (TOURVIEILLE, 1982).

\section{TABLEAU 5}

Délais moyens (en heures) d'apparition des symptômes sur rameaux de pommier maintenus en survie en présence d'extraits purifiés des différents organes de jeunes plants de pommier morts de pourridié laineux (tous isolats confondus - 25 répétitions).

Average time (in $h$ ) necessary for symptom appearance on apple branches growing in extracts made from different parts of young apple plants killed by white root rot (for all $\mathrm{R}$. necatrix strains - 25 replicates).

\begin{tabular}{ccccc}
\hline \hline & \multicolumn{5}{c}{ Classe des symptômes } \\
\cline { 2 - 5 } Extraits & 1 & 2 & 3 & 4 \\
\cline { 2 - 5 } & 51 & 58 & 69 & 83 \\
Racines & 62 & 78 & 94 & - \\
Tiges & 79 & - & - & - \\
Feuilles & 23 & 31 & 37 & 42 \\
Témoin filtrat de & & & & - \\
culture (Rn 17) & & - & - & \\
\hline $\begin{array}{c}\text { Témoins pommiers } \\
\text { sains }\end{array}$ & 96 & & \\
\hline \hline
\end{tabular}

- Les enzymes : BÄRTSCHI et al. (comm. pers., 1979 ) ont montré qu'en culture in vitro, $R$. necatrix est moins bien équipé du point de vue enzymatique pour dégrader la cellulose que pour dégrader les composés pectiques et que plusieurs phases d'activité enzymatique peuvent être reliées aux différentes phases de la croissance mycélienne. Ces résultats sont vraisemblablement l'indice d'une activité séquentielle au cours des processus d'infection des racines.

- Les toxines.

L'importance relative de ces 3 facteurs varie certainement selon les phases de l'infection :

- Phases de pré-pénétration et de pénétration : les phénomènes mécaniques jouent probablement un rôle très important. Cependant, les enzymes interviennent certainement, particulièrement au cours de la pénétration des jeunes racines et des plantes charnues riches en composés pectiques. Toutefois, il faut remarquer qu'après la pénétration les cellules sont envahies par le champignon bien avant d'être désorganisées par la destruction des lamelles moyennes (TOURVIEILLE, 1982) ; cela signifie peut-être que les processus toxiques sont alors plus rapides que les actions enzymatiques.

- Phase de généralisation s'achevant par la mort de la plante ; à ce stade, l'intervention des toxines est sans doute capitale chez le pommier. Cependant, l'avancement des «cordons subcorticalis » qui décollent le suber et la destruction de l'écorce des racines par pectinolyse et cellulolyse se poursuit pendant cette phase (TOURVIEILLE, 1982).

Il est à remarquer que les auteurs français du début du siècle citaient $R$. necatrix comme responsable de dégâts importants sur les arbres fruitiers à noyau et affirmaient qu'il était peu dommageable sur pommier. Les observations que l'on peut faire actuellement en France amènent aux conclusions inverses (GUILLAUMIN et al., 1982). Ne serait-il pas possible que les isolats aient été sélectionnés par rapport à leur capacité à produire des toxines? Ainsi, les isolats produisant actuellement des toxines seraient très pathogènes sur pommier et beaucoup moins sur les arbres à noyau, sans doute peu sensibles aux toxines du Rosellinia comme le laissent penser les résultats obtenus sur le cerisier.

Chez d'autres hôtes, ces toxines ont, sans doute, un rôle tout à fait secondaire. La destruction enzymatique de l'« écorce » du système racinaire (et surtout du liber) doit alors jouer le rôle principal.

Par ailleurs, le champignon ne semble pas s'installer dans le bois, ni le dégrader. Il ne posséderait pas de systèmes ligninolytiques et ses systèmes cellulolytiques seraient incapables de dégrader la cellulose associée à la lignine.

\section{CONCLUSION}

Les isolats de $R$. necatrix étudiés produisent in vitro des substances phytotoxiques. Ces substances sont extraites du filtrat de culture (ajusté au pH 7) par le chloroforme, puis partiellement purifiées sur plaque de chromatographie. Elles ont reproduit sur rameaux de pommier une partie des symptômes du pourridié laineux : nécrose des nervures et dessèchement du 
limbe. Le flétrissement et la décoloration des feuilles, qui sont souvent observés lors d'attaques de pommier par $R$. necatrix, sont sans doute liés aux désordres physiologiques provoqués par la destruction du système racinaire.

Ces toxines sont également produites par le champignon à l'intérieur du végétal infecté. Elles sont absentes de la plante saine. Leur présence dans les organes non envahis par le mycélium (tige et feuilles) indique qu'elles sont véhiculées par la sève.

La spécificité d'action de ces toxines ne correspond pas à celle du champignon. Ainsi, les cerisiers, le jasmin et la pivoine sont peu sensibles aux toxines alors qu'ils sont affectés par le pourridié laineux. Cependant, sur les Malus, on observe une correspondance entre la sensibilité des génotypes de l'hôte au pathogène et aux toxines. Il apparaît également une corrélation entre le pouvoir pathogène des différents isolats et leur aptitude à produire des toxines mais, sur ce point, nous devons conclure avec prudence à cause de la grande homogénéité de nos isolats. Nous ne possédons pas d'isolats ne produisant pas de toxines ou en produisant en faibles quantités.
Nous ne pouvons pas parler de pathotoxines telles qu'elles sont définies par les pathologistes. Si les toxines de $R$. necatrix jouent un rôle dans le développement de la maladie sur le pommier, elles ne sont pas des déterminants primaires de celle-ci.

Cependant, les premiers résultats obtenus sur quelques génotypes de Malus laissent entrevoir une utilisation possible de ces toxines par le sélectionneur : la mise au point de méthodes de sélection des portegreffes de pommier pour leur résistance au pourridié laineux, basées sur des tests de résistance aux toxines produites par Rosellinia. La sélection serait facilitée par une meilleure purification de ces dernières, ainsi que par leur identification chimique. Nous ignorons si les produits que nous avons extraits appartiennent aux dicétopéperazines, molécules identifiées par CHEN (1960), ou à la cytochalasine E produite également par Rosellinia et phytotoxique pour le pommier (SAWAI et al., 1982).

Reçu le 9 janvier 1985. Accepté le 15 octobre 1985.

\section{RÉFÉRENCES BIBLIOGRAPHIQUES}

Abe T., Kono M., 1955. Studies on the white root rot of tea bush. III : On the effect of composants of culture media to the fungal growth, and the phytotoxicity of the filtrate of liquid media used by the fungus. Sci. Rep. Fac. Agric. Saikyo Univ., 7, 49-56.

Abe T., Kono M., 1957. Studies on the white root rot of tea bush. IV : On the toxicities of cultural filtrate of the fungus. Sci. Rep. Fac. Agric. Saikyo Univ., 8, 74-80.

Chen Y. S., 1960. Studies on the metabolic products of Rosellinia necatrix Berl. Part I. Isolation and characterization of several physiologically active neutral substances. Bull. Agric. Chem. Soc. Jap., 24 (4), 372-381.
Guillaumin J. J., Mercier S., Dubos B., 1982. Les pourridiés à Armillariella et Rosellinia en France sur vigne, arbres fruitiers et cultures florales. I. Etiologie et symptomatologie. Agronomie, 2 (1), 71-80.

Sawai K., Okuno T., Ito T., 1982. The toxicity of cytochalasine E on plants. Ann. Phytopathol. Soc. Jap., 48, 529-531.

Tourvieille de Labrouhe D., 1982. Pénétration de Rosellinia necatrix (Hart.) Berl. dans les racines du pommier en conditions de contamination artificielle. Agronomie, 2 (6), 553-560. 